\title{
Optical Technologies in Support of the Smart City Concept
}

\author{
SUZANA D. MILADIĆ-TEŠIĆ, University of East Sarajevo, \\ Review paper \\ Faculty of Transport and Traffic Engineering, \\ Doboj, Bosnia and Herzegovina \\ UDC: 004.738.45:621.391.6 \\ DOI: 10.5937/tehnika2002209M
}

GORAN Z. MARKOVIĆ, University of Belgrade,

Faculty of Transport and Traffic Engineering, Belgrade

NIKOLA P. NONKOVIĆ, University of Belgrade, Belgrade

Globalization and technological advances have made significant changes in city development. To integrate all dimensions of the smart city, communication networks are essential. Smart infrastructure integrates transport, electricity, water distribution, sensing systems, information and communication technologies with communication networks. To make optimal use of all the data available from a range of sensors smart cities need reliable networks. This paper gives an overview of optical technologies for application in smart systems and infrastructures that should handle the capacity of data and smart city applications.

Key words: optical technologies, smart city, network infrastructure

\section{INTRODUCTION}

According to the projections of the United Nations, continuing urbanization will add 2.5 billion people to the world's urban population by 2050 [1]. This means that about $70 \%$ of the world's future population is expected to live in cities. Currently, the most urbanized regions include Northern America (with $82 \%$ ), Latin America and the Caribbean (81\%), Europe (74\%) and Oceania $(68 \%)$ [1].

Dynamic growth of population in cities and adopting the urban lifestyle brings a range of complex problems to be solved and at the same time requires a new concept of a city, called ,smart city“. To meet the needs of the urban population and to improve the quality of life, emerging technologies and innovations are giving new opportunities and trigger the transformation of a city into a smart city.

Information and communication technologies (ICT) have been developed exponentially but the smart

Author's address: Suzana Miladić-Tešić, University of East Sarajevo, Faculty of Transport and Traffic Engineering, Doboj, Vojvode Mišića 52, Bosnia and Herzegovina

e-mail: miladics@ hotmail.com

Paper received: 25.02.2020.

Paper accepted: 13.03.2020. city concept is under development and the subject of extensive research. The key role in this concept will play telecommunications and connectivity because a huge amount of data must be acquired, stored and analyzed to gain the desired benefits. In this regard, cities are required to develop high capacity infrastructure to collect and store the data, connect to the Internet and use the data gathered from sensors as much as possible. All these will depend on high speed, low latency and reliable communication networks running on fiber technology because it is the only candidate that can handle the capacity of upcoming data and applications. Fiber optic communications provide huge bandwidth, longer transmission distances, and better signal immunity. Therefore, the copper twisted pairs and coax cables for data and video transmission requirements are widely replaced with fibers. The goal of this paper is to give an overview of optical technologies and their role in support of the smart city concept.

The rest of the paper is structured as follows. The second section introduces some definitions and features of a smart city. The third section provides an overview of $5 \mathrm{G}$ optical infrastructure and its role in the smart city concept. Some standardization issues and future challenges that should be solved to make a smarty city concept successful are given in the fourth section. The fifth section concludes the paper. 


\section{SMART CITY CONCEPT}

\subsection{Definition and characteristics}

Defining a smart city is not as easy as it is broad in scope and because of different viewpoints. There are a lot of available but not standardized definitions in the literature. The criteria that cities should meet to be considered as smart are different depending on the region because every city has a different development level, current and future characteristics. Intending to establish a concrete definition for smart sustainable cities that can be used worldwide, the International Telecommunication Union's (ITU) focus group on smart sustainable cities (FG-SSC) - working group 1 has analyzed definitions on smart cities. Based on the above analysis, the approved definition is as follows: „A smart sustainable city is an innovative city that uses information and communication technologies (ICTs) and other means to improve quality of life, efficiency of urban operation and services, and competitiveness, while ensuring that it meets the needs of present and future generations concerning economic, social and environmental aspects" [2].

Several international studies, including the one carried out by the Vienna University of Technology [3] and the study of the European Parliament [4], define the smart city as a city able to operate, effectively, through policies and actions relating to six different smart features: environment, economy, living, people, mobility, governance. Considering the world level, Berrone et al. [5] evaluated 181 cities in more than 80 countries to determine the smartest cities around the world. According to the index results, the City of New York, London and Paris are at the top of the list while San Francisco, Boston, Amsterdam, Chicago, Seoul, Geneva, and Sydney round out the top 10 [5].

To better explain the smart city concept, the European model [3] is presented with the main characteristics of a smart city. According to [3] a smart city is a city well performing in 6 key characteristics (given in Fig. 1) which are further used for city evaluation and ranking in their process of urbanization.

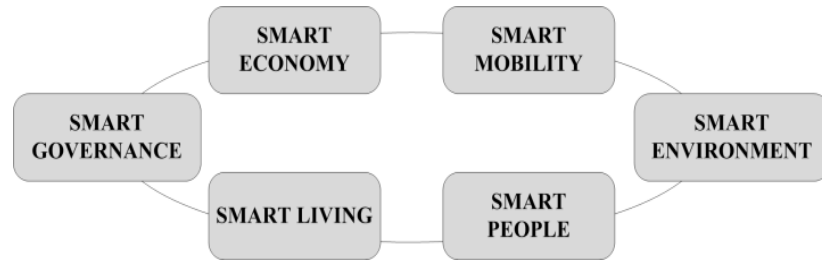

Figure 1 - Characteristics of a smart city

Each included characteristic is defined by several factors and each factor is described by some indicators (an example is shown in Table 1 with smart mobility characteristic). These characteristics and indicators are the frameworks for the assessment of a city's performance as a smart city.
Table 1. An example list of factors and indicators [3]

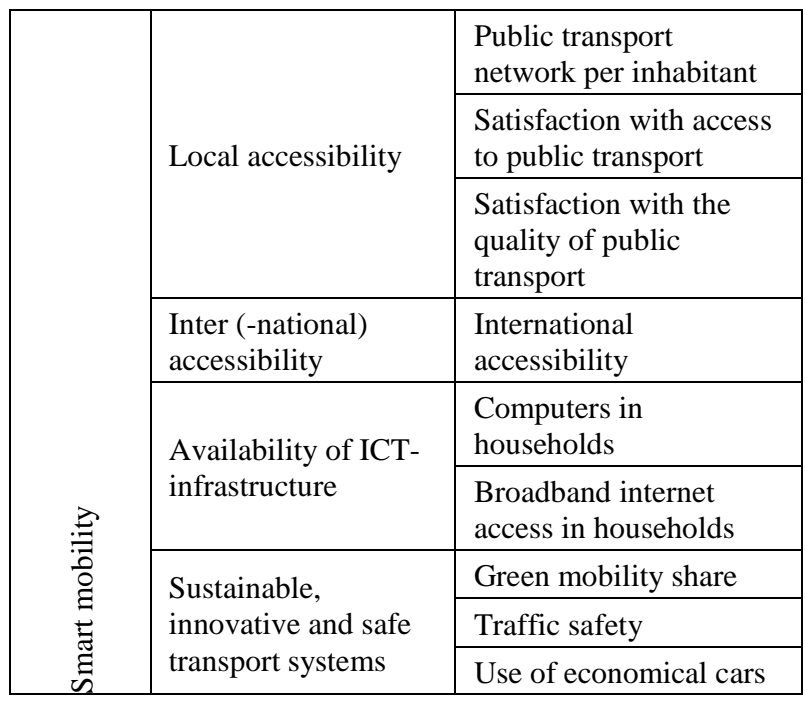

The European model uses the data obtained from public and freely available databases. To be comparable, the values of different indicators were standardized and aggregated [3]. Based on this analyses city profiles are obtained showing its strengths and weaknesses. Also, the city ranking is used for benchmarking with other cities. An example of a city profile is given in Figure 2. It is worth to mention that every city develops the characteristic that is of its most interest. Because every city is unique, some will highlight and invest in energy efficiency while others in smart transportation or waste management. Currently, there is a growing trend in intelligent transportation systems where transportation planners are focusing on smart traffic lights to improve the traffic flow and set up high-resolution cameras to manage the flow of cars, buses, public service vehicles, bicycle traffic or pedestrians. The literature analyses show that several related city concepts are appearing and overlapping with the smart city concept such as intelligent, knowledge, sustainable, talented, wired, digital and eco-city. According to [4] the term ,smart city" has become dominant among the mentioned, especially at the city level, globally as well as in Europe.

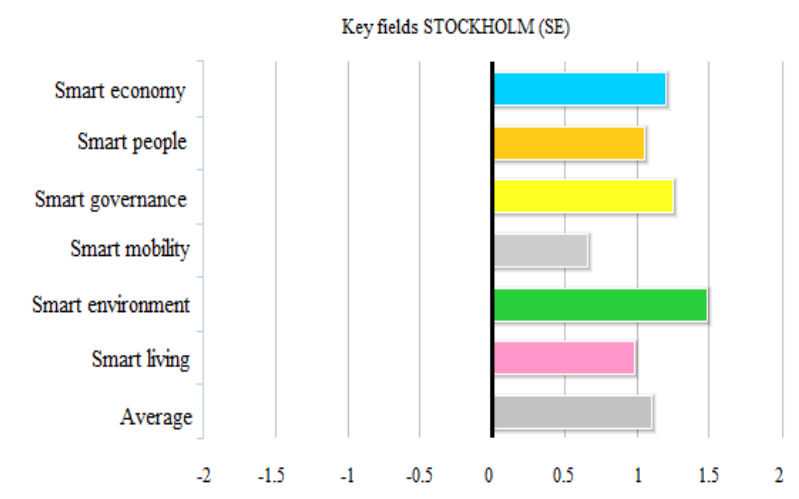

Figure 2 - Example of a city profile (Stockholm) [3] 


\subsection{Smart city architecture}

To make a city smart, several layers figure in its architecture (Fig. 3) that enables all the performances. The layers are the following [6-8]:

- Sensing or device layer - the data are collected from devices, sensors, and actuators. More sensors combined with fibers and switches make a sensor network and it is preferred as much coverage as possible with these connected devices.

- The network layer - includes transport and networking capability. Transport capability provides connectivity for the transport of services, carrying the data to the upper layers. The networking capability provides relevant control functions of network connectivity such as access and transport resource control functions, mobility management or authentication.

- Service and application support layer - the layer where the collected data are organized, analyzed and filtered. The decisions are made based on this data processing. It offers support functions to different applications.

- Application layer - the layer directly interacted with citizens and contains all smart city applications (smart transportation, smart weather, smart healthcare...). The optimal stored and analyzed data are used on this layer.

\begin{tabular}{|c|c|c|c|}
\hline \multicolumn{4}{|c|}{ APPLICATION LAYER } \\
\hline Smart health & Smart transport & Smart living $\mathrm{Sr}$ & Smart energy ..... \\
\hline \multicolumn{4}{|c|}{ SERVICE AND APPLICATIONS SUPPORT LAYER } \\
\hline \multicolumn{4}{|c|}{ NETWORK LAYER } \\
\hline \multicolumn{4}{|c|}{ Networking capabilities } \\
\hline Network layer a & d protocols & Routing Transpor & Transport layer and protocols \\
\hline Physical layer & \multicolumn{2}{|c|}{ Transport capabilities } & Data-link layer layer \\
\hline Wireless LAN & $\begin{array}{r}\text { Optical PAN } \\
\text { Optical access }\end{array}$ & $\begin{array}{c}\text { Optical LAN } \\
\text { Optical transport }\end{array}$ & $\begin{array}{l}\text { Copper access } \\
\text { Wireless/radio access }\end{array}$ \\
\hline \multicolumn{4}{|c|}{ DEVICE/SENSING LAYER } \\
\hline & $\begin{array}{l}\text { Electromagneti } \\
\text { Optical sens } \\
\text { Thermoelectric }\end{array}$ & $\begin{array}{l}\text { ic sensors and act } \\
\text { sors and actuato } \\
\text { sensors and actu }\end{array}$ & \\
\hline
\end{tabular}

Figure 3 - The architecture of a smart city [adapted from 6, 7, 8]

It could be seen from Figure 3 that optical technologies find a place at the device and network layer (transport part). Having in mind that smart applications require distance between the location where the information is collected and the location where the information is stored, smart city must include massive fiber optic backbones to support small cells, Internet service providers and fiber to the home as well as private communications networks for city services (demonstrated in Figure 4).

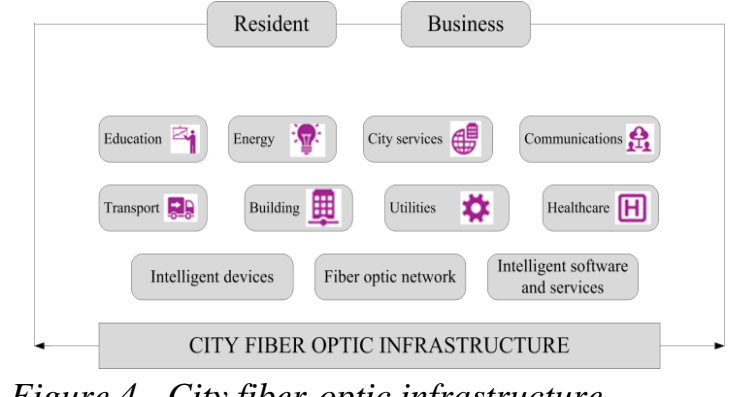

Figure 4 - City fiber-optic infrastructure

\section{TOWARDS 5G OPTICAL NETWORK INFRASTRUCTURES}

Over the last few years, there has been an exponential growth in traffic volume in optical transport networks, primarily due to the development of the Internet and new IP (Internet Protocol) services. The new generation of optical networking, known as elastic/flexible optical networking or 5G generation of optical networks, emerged as a result of the rapid growth of applications and smart infrastructures. New applications make the new criteria in latency, bandwidth requirements and security. Currently deployed DWDM (Dense Wavelength Division Multiplexing) technology with fixed spectrum allocation will not be able to cope with ongoing and future demands. Migration to flexible networks, in whole or part, is expected in the near future.

\subsection{Flexible networks}

Like mobile communication systems where development has been presented by generations, optical communication systems have also been developed throughout generations.

Table 2. Functionalities of particular optical network generations [6]

\begin{tabular}{|l|l|l|l|}
\hline Generation & Technology & Characteristics & $\begin{array}{l}\text { Line data } \\
\text { rates }\end{array}$ \\
\hline 3rd & $\begin{array}{l}\text { SDH, } \\
\text { SONET } \\
\text { over WDM }\end{array}$ & $\begin{array}{l}\text { Ring and mesh } \\
\text { topology, fixed } \\
\text { wavelength grid, } \\
\text { p-t-p links }\end{array}$ & $\begin{array}{l}50 \mathrm{Mb} / \mathrm{s}-40 \\
\mathrm{~Gb} / \mathrm{s}\end{array}$ \\
\hline th & $\begin{array}{l}\text { OTN, } \\
\text { DWDM, } \\
\text { ROADM, } \\
\text { 100G } \\
\text { Ethernet }\end{array}$ & $\begin{array}{l}\text { Ring and mesh } \\
\text { topology, fixed } \\
\text { wavelength grid, } \\
\text { ODU switching }\end{array}$ & $1-100 \mathrm{~Gb} / \mathrm{s}$ \\
\hline 5 th & $\begin{array}{l}\text { EON, } \\
\text { SDN, } \\
\text { Optical } \\
\text { cloud }\end{array}$ & $\begin{array}{l}\text { Mesh topology, } \\
\text { adaptive } \\
\text { modulation, } \\
\text { flexible grid, } \\
\text { energy efficiency }\end{array}$ & $10 \mathrm{~Gb} / \mathrm{s}-1$ \\
$\mathrm{~Tb} / \mathrm{s}$
\end{tabular}

SDH- Synchronous Digital Hierarchy; SONET- Synchronous Optical Network; OTN- Optical Transport Network; ROADMReconfigurable Optical Add/Drop Multiplexer; EON- Elastic Optical Network; SDN- Software-Defined Networking. 
Some functionalities and comparison of $3^{\text {rd }}, 4^{\text {th }}$ and $5^{\text {th }}$ generation (we excluded the older generations due to its maturity) are shown in Table 2.

Smart city applications require a large amount of bandwidth and from the provider's point of view, its efficient utilization is an imperative task. Therefore, the first step towards $5 \mathrm{G}$ optical network infrastructure is to replace fix grid with flexible grid technology. In the context of the fixed grid, a part of a spectrum has been always wasted because the whole spectrum is allocated to demand without considering its size. The channel (wavelength) spacing is equal. A flexible grid means that some parameters such as channel spacing or modulation schemes become adaptable. There is no spectrum wastage because its allocation considers the size of demand. According to ITU recommendation G. 694.1 [9] the traditional DWDM fixed grid of $50 \mathrm{GHz}$ and $100 \mathrm{GHz}$ has been replaced with a flexible grid of $25 \mathrm{GHz}, 12.5 \mathrm{GHz}$ or $6.25 \mathrm{GHz}$. The concept with spectrum savings of $37.5 \mathrm{GHz}$ used instead of $50 \mathrm{GHz}$ is shown in Fig. 5.

It could be seen from Figure 5 that the whole spectrum is segmented into parts (called slots or slices in the literature) and that optical paths are allocated a proper number of slots according to bandwidth on demand.

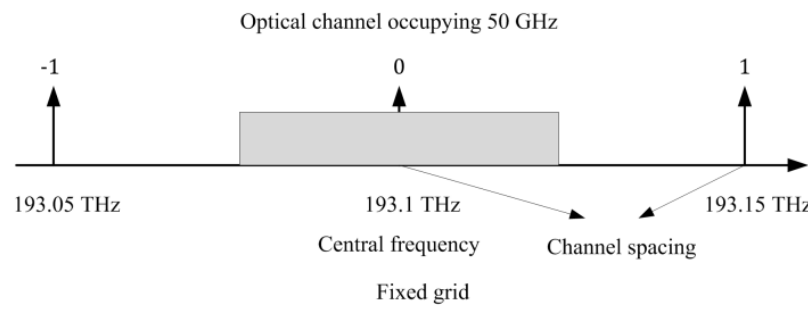

Optical channel occupying $37.5 \mathrm{GH} z$

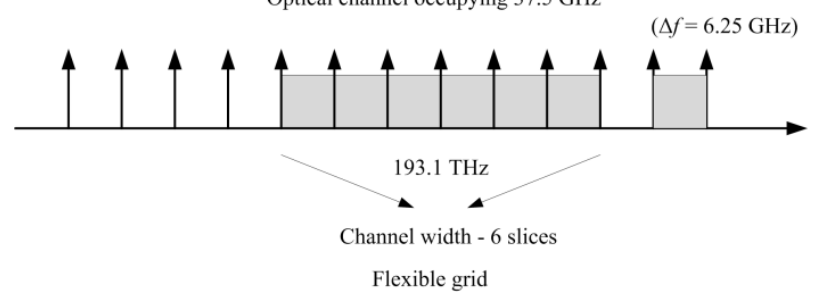

Figure 5 - Fix and flexible grid features [9]

\subsection{Key enabling components for $5 G$ optical transport networks}

The flexibility of optical infrastructure requires developing new components and methods for increasing capacity.

Elastic network architecture requires application of optical links of high capacity and specific hardware elements such as BV-WXC, bandwidth variable wavelength cross-connect) for routing optical paths; ROADM, reconfigurable optical add/drop multiplexers for dynamic wavelength separation and forwarding without optoelectronic conversion in nodes as well as adaptive optical transmitters and receivers BVT, (Bandwidth Variable Transponder), which are softwareadaptable to the central frequency, number of slots and modulation type of the incoming signal. Such BVT can provide different modulation formats such as binary phase-shift keying (BPSK), quadrature phase-shift keying (QPSK) and quadrature amplitude modulation (QAM) operating on flexible wavelength grid with $12.5 \mathrm{GHz}$ spectral separation and $6.25 \mathrm{GHz}$ granularity for central frequencies [10].

Flexible optical nodes will be required to provide elasticity in wavelength, space and time domain and to support elastic switching over a flexible grid. The concept of elasticity could be partially added to the nodes where bottlenecks occur.

\subsection{Combination of radio wireless and optical access networks}

Optical networks have the advantage of providing high bandwidth while radio wireless networks provide mobility. To achieve the concept of everyone and everywhere, 5G radio wireless networks use small base stations (femto or pico-cells) or heterogeneous networks (HetNets). For the implementation of front-haul and back-haul to base stations microwave links, digital subscriber lines (xDSL), time-division multiplexed (TDM) leased lines or asynchronous transfer mode (ATM) are used mostly [6]. The problem of these networks is the variations in channel quality, interference, and energy inefficiency.

Also, data rates over tens of $\mathrm{Gb} / \mathrm{s}$ required in $5 \mathrm{G}$ networks are not possible with these conventional methods. Instead, high data rates, as well as energy efficiency, are possible with optical access networks which could be considered for backhaul to fifth-generation wireless networks.

For this purpose, passive optical networks (PON) are widely deployed because they inherently support split ratios up to 1:256 and for further development, the emerging standards NG-EPON (IEEE) and G.hsp.x (ITU-T) are considered to be supporting technologies [6]. The main prerequisite is installed optical fiber which is not always practical or economically justified. That is why a tradeoff must be found between installing these types of infrastructures.

An emerging technology that has gained much attention from research perspectives from the set of optical wireless communications (OWC) is a VLC (Visible Light Communication) technology used to complement current radio systems.

VLC is particularly of interest because the same visible light used for lighting is also used for communication. Compared to the radio communication system, VLC has the advantage in broad frequency 
spectrum free from regulation and without restrictions on bandwidth allocation, the communication occurs point to point utilizing transmitters and receivers, components are easily found in the market at reasonable prices, and it is characterized with less interference and power-consuming. VLC has been standardized with IEEE 802.15.7 and therefore considered for V2V (Vehicle-to-Vehicle) communications, smart lighting as well as for navigation in urban areas where GPS (Global Positioning System) signal is weak or does not exist due to the proximity of very tall buildings or tunnels. The integration of VLC technology with Intelligent Transport Systems (ITS) can significantly improve many spheres of traffic and transportation due to the presence of vehicle lights and existing traffic light infrastructure.

Due to several challenges that need to be addressed in the future, VLC is still not expected to replace RF (Radio Frequency), but rather complement it in the context of heterogeneous networks where the best of both in ITS scenario should be used.

\subsection{Energy efficiency issue}

The energy consumption of telecom networks is drastically increasing with the increase in traffic. 5G optical infrastructures except spectrum efficient require power efficient structures to minimize total power consumption. The implementation and requirements of a particular smart application must consider all parts of the system when analyzing energy consumption. Therefore, the elements that should be included are the sensing elements, devices involved in data transmission and networking within access and core areas as well as devices related to data storage and processing such as network and application servers. The main energy consumers are active components such as IP routers, optical transponders, and optical amplifiers.

Compared to wireless and copper wires, optical technologies provide higher energy efficiency. First, because of the flexibility property, some subcarriers are possible to be excluded or switched off in a sleep mode when not needed in a network. Secondly, the number of transmitters could be minimized with the use of some traffic engineering techniques such as grooming.

The decrease in power consumption could be achieved through the use of some types of optical sensors when designing sensor nodes and battery lifetime. Also, fiber infrastructure is possible to be shared in a way that optical links can be used for sensing and carrying signals for data transmission at the same time because the data and sensor signals are separated with WDM technology. The operating principle of optical sensors is the transmitting and receiving of light and the object to be detected reflects a light beam sent out by an emitting diode. Optical sensors are usually applied in the measurement of physical quantities such as temperature, velocity, acceleration, strain, pressure; monitoring the health; measurement of various chemical properties; biomedical and industrial applications [6].

\subsection{Software-defined optical networks}

Software-Defined Networks (SDN) provide the complete separation of control and data plane (user plane). The separation simplifies the network design and operation because instructions are provided by SDN controllers instead of multiple protocols [11]. If a failure occurs on the control plane connections, there is no problem in the delivery of user data.

Smart application requirements are changing over time and it leads to the rise of cloud computing where access to software, storage, and infrastructure is done on demand. Therefore, bandwidth provisioning for such applications should be done on demand. For dynamic provisioning, managing resources and optimization of multiple layers, SDNs are possible to be extended to optical networks (layer 0/optical layer). The main goal of introducing the control plane into the optical transport network is the ability to dynamically establish and maintain a connection through which the service is delivered from one point to another. According to [11]

Software-Defined Optical Network (SDON) is the one with dynamic optical networking enabled by SDN. SDN controllers communicate through the control channels providing path computation and transport technology across several layers best suited to carry traffic. This could be achieved through the implementation of PCE (Path Computation Element) in SDN controllers as a software module. Multilayer SDN can monitor and evaluate the performance at each layer and across several network areas and dynamically reroute traffic or add some bandwidth from a lower layer to avoid congestions [10].

Although, SDNs have been originally focused on packet-switched networks and applications in data center networks, BVTs and ROADMs incorporating wavelength-selective switches (WSS) are the optical components whose parameters can be adapted and controlled by software. These parameters include the type of modulation, central frequency or the number of frequency slots belonging to a channel.

To support cloud applications, the interconnection of large cloud data centers using optical technologies seems to be a promising solution because of the high capacity and low latency. Multilayer SDN can open the way for dynamic network optimization as well as for automated congestion control and cost management [10]. 


\section{STANDARDIZATION AND CHALLENGES FOR SMART CITIES}

Smart city applications require standardization and device interoperability. The leading standardization bodies included in this task are Internet Engineering Task Force (IETF), Third Generation Partnership Project (3GPP), European Telecommunications Standards Institute, (ETSI) and IEEE. Each of them deals with some activities to enable the smart city concept to citizens. IETF works mostly on routing protocols for low power networks. 3GPP works on providing better network coverage. The global initiative of ETSI called oneM2M (machine-to-machine) aims to develop a single horizontal platform for enabling interoperability among all applications through a distributed software layer [12]. IEEE focuses on optimization of the air interface for ultra-IoT deployments and the use of a sub-6 GHz spectrum for IoT connectivity to support numerous smart city applications.

There are several opened issues and research directions that should be addressed to make the smart city idea and its functional technologies successful:

- Security - issue required for every smart device. Solutions that ensure data authenticity and secure communication between devices and cloud-based application centers should be designed.

- Interoperability identified at different levels - an issue that plays a crucial role and presents the main barrier for smart city success according to [13] due to the lack of universal standards. It refers to the capability of two different smart devices and networks to communicate with each other for the exchange of information. The devices usually belong to different domains and operate with different communication technologies. For example, ITS mostly utilize DSRC (Dedicated Short Range Communication) while some applications use WLAN as the underlying communication protocol. To overcome this barrier, interoperability should be identified at different levels: the device, network, communication, application, and platform level.

- Low power device construction - smart devices are equipped with sensors that require energy. To decrease the energy consumption as well as its costs, the solutions related to battery lifetime increasing and microelectronics should be considered.

- Data analytics - a huge amount of data obtained from connected devices must be analyzed, extracted and used for decision making. For this purpose, intelligent learning algorithms must be adopted.

\section{CONCLUSION}

The basis of any smart city is a modern smart infrastructure that is composed of devices that are connected through telecom networks back to data centers, where all the data gathered from devices are stored. These data are leveraged by various systems and platforms to make decisions and initiate activities, and to address the needs of users via services and applications.

Because of high capacity and low latency advantage, optical technologies applied independently or combined with wireless, are the promising solutions in support of smart city concept.

The paper briefly overviewed optical technologies and their role in smart city infrastructure and some opened issues to be solved in order to make smart city concept successful.

\section{REFERENCES}

[1] United Nations Department of Economic and Social Affairs. World Urbanization Prospects 2018: Highlights, ST/ESA/SER.A/421, 2018.

[2] ITU-T Focus Group on Smart Sustainable Cities. Smart sustainable cities: an analysis of definitions, FG-SSC Technical report, ITU, Geneva, 2014.

[3] http://www.smart-cities.eu/?cid=2\&ver=4

[4] European Parliament. Mapping smart cities in the EU, Study, available at: https://www.europarl.europa.eu/committees/en/supporting-analyses-search.html, 2014.

[5] Berrone P. et al. New York edges out London as the world's smartest city, IESE insight review. 2016.

[6] Aleksić S, A survey on optical technologies for IoT, smart industry and smart infrastructures, Journal of Sensor and Actuator networks, Vol. 8, No. 47, pp. 118, 2019.

[7] ITU-T Y.2060. Overview of the Internet of Things, Recommendation. available at: https://www.itu.int/rec/T-REC-Y.2060-201206-I, 2012.

[8] Silva B. N. et al. Towards sustainable smart cities: A review of trends, architectures, components, and open challenges in smart cities, Sustainable Cities and Society, Vol. 38, pp. 697-713, 2018.

[9] ITU-T G.694.1. Spectral grids for WDM applications: DWDM frequency grid, v2.0. Recommendation, 2012, available at: https://www.itu.int/rec/TREC-G.694.1/ 
[10]Aleksić S, Towards fifth-generation (5G) optical transport networks, in Proc. 17th International Conference on Transparent Optical Networks (ICTON), IEEE, Budapest, pp. 1-4, 2015.

[11]Bhaumik P. et al. Software-defined optical networks (SDONs): a survey, Photonic Network Communications, Vol. 28, pp. 4-18, 2014.
[12]Mehmood Y. et al. Internet-of-Things based smart cities: recent advances and challenges, IEEE $\mathrm{Co}$ mmunications Magazine, Vol. 55, No. 9, pp. 16-24, 2017.

[13]World Economic Forum Industrial Internet Survey. Industrial Internet of Things: unleashing the potential of connected products and services, Technical report, january 2015

\section{REZIME}

\section{OPTIČKE TEHNOLOGIJE KAO PODRŠKA KONCEPTU PAMETNIH GRADOVA}

Globalizacija i razvoj tehnologija značajno su uticali na razvoj gradova. Kako bi se integrisali svi elementi pametnog grada u jednu celinu, esencijalnu ulogu imaju komunikacione mreže. Pametna infrastruktura integriše sistem transporta, snabdevanja strujom, vodom, senzorski sistem, informacionokomunikacione tehnologije sa komunikacionim mrežama. Kako bi se optimalno iskoristili svi podaci prikupljeni od niza senzora, neophodne su pouzdane mreže. Ovaj rad daje pregled optičkih tehnologija koje se mogu primeniti u konceptu pametnih gradova i infrastruktura, a koje omogućavaju povećane brzine prenosa i podršku aplikacijama koje se očekuju u budućem periodu.

Ključne reči: optičke tehnologije, pametni grad, mrežna infrastruktura 